\title{
Scabies among primary schoolchildren in Egypt: sociomedical environmental study in Kafr El-Sheikh administrative area
}

This article was published in the following Dove Press journal:

Clinical, Cosmetic and Investigational Dermatology

24 February 2015

Number of times this article has been viewed

\author{
Doaa Salah Hegab' \\ Abdullah Mahfouz Kato' \\ Ibrahim Ali Kabbash ${ }^{2}$ \\ Ghada Maged Dabish ${ }^{3}$ \\ 'Department of Dermatology and \\ Venereology, Faculty of Medicine, \\ ${ }^{2}$ Department of Public Health and \\ Community, Faculty of Medicine, \\ ${ }^{3}$ Faculty of Medicine, Tanta University, \\ Tanta, Egypt
}

Background/objectives: Scabies is a major global public health issue that might affect people from all socioeconomic levels. The primary contributing factors in contracting scabies seem to be poverty and overcrowded living conditions. Scabies often spreads among schoolchildren quite rapidly, owing to their close contact and overcrowding within the schools. However, limited information is available about its risk factors and the socioeconomic correlates among schoolchildren in Egypt. This study aimed to assess the prevalence of scabies and its risk factors among primary schoolchildren in Kafr El-Sheikh administrative area, Egypt.

Methods: This cross-sectional descriptive study was performed on primary schoolchildren in urban and rural areas of Kafr El-Sheikh administrative area. A predesigned questionnaire was used for data collection from the randomly selected 2,104 children, and clinical dermatological examination was done for them.

Results: Out of 2,104 children studied, there were 92 cases of scabies with a prevalence of $4.4 \%$. The prevalence of scabies infestation in male students was $3.9 \%$, while it was $4.8 \%$ in females, with no statistical significance. The results showed significant variations in the risk of scabies infestation by factors such as residence, paternal education and occupation, maternal education, sleeping with others, having animals at home, dealing with animals outside the house, type of building for living, family history of itchy rash, and sharing clothes with others.

Conclusion: In our community, scabies is still an important health problem affecting schoolchildren, especially in rural areas. It is characterized by a complex web of causation, particularly poor living conditions and low level of parents' education.

Keywords: child, prevalence, risk factors, scabies, social conditions

\section{Introduction}

Scabies is a common parasitic infection caused by the mite Sarcoptes scabiei. Scabies affects about 300 million people worldwide yearly. ${ }^{1}$ Epidemiological studies indicated that the prevalence of scabies is not affected by sex, race, or age, and that the primary contributing factors in contracting scabies seem to be poverty and overcrowded living conditions. ${ }^{2,3}$

Although the diagnosis of scabies in our third world communities and endemic areas is often easy and straight forward, it could be sometimes one of the most difficult diagnoses in dermatology. Scabies is easy to misdiagnose with other skin problems that are common among schoolchildren, such as papular urticaria, atopic dermatitis, and contact eczema. Epidemiological history, family history, occurrence of itching, which is most severe at night, and distribution of the lesions form the basis of the diagnosis. $^{4}$
Correspondence: Doaa Salah Hegab Department of Dermatology and Venereology, Faculty of Medicine, Tanta University Hospitals, El Geish Street, Tanta 3 IIII, Egypt Tel +20 I2 24500857

Email doaasalahhegab@yahoo.com 
Infectious skin diseases and infestations like pediculosis and scabies are a common problem in schoolchildren owing to close contact between classmates. Unfortunately, epidemiologic studies of skin diseases in schoolchildren are limited in Egypt, and assessment of their burden and patterns at schools may improve care through school health programs. ${ }^{5,6}$

The aim of this study was to estimate the prevalence of scabies and its risk factors among primary schoolchildren in Kafr El-Sheikh administrative area, Egypt.

\section{Materials and methods}

This cross-sectional descriptive study was conducted in Kafr El-Sheikh administrative area, which is the capital of Kafr El-Sheikh Governorate that lies in the northern part of Egypt, along the western branch of the Nile in the Nile Delta. This administrative area includes 9 major villages, 38 small villages, and 246 manors. The study was approved by the local ethics committee of The Faculty of Medicine, Tanta University, and by the educational department in the study settings. The study was conducted between September 2013 and February 2014 (autumn and winter seasons) during the school months.

\section{Sampling}

The sample size was determined using the Epi-Info program. The calculated sample size was 454 at $80 \%$ power and $95 \%$ level of confidence, with expected prevalence of scabies of $5 \%$ and a margin of error of $2 \%$. The sample size was increased to 500 to improve the validity of results. A fourfold increase in the sample $(2,104)$ was done to correct errors due to the clustering effect. The multistage sampling technique was used, whereby schools were stratified into two strata, urban primary and rural primary.

Schools were chosen randomly from each stratum to represent female and male students. A total of 862 students were chosen randomly from 5 urban schools, and 1,242 students were chosen randomly from 8 rural schools. All the schoolchildren chosen were from grades 4 to 9 primary because younger children (grades 1-3) were not able to understand and answer the questionnaire. None of the selected children declined to participate in the study (response rate 100\%).

First, approval was sought from the headmaster of each of the selected schools. The schoolteachers were asked to help in organizing the interview sessions. A predesigned questionnaire was used, which included:

- Sociodemographic and environmental data: the level of education and the occupations of their parents, number of members of their families, number of rooms in their houses, number of persons who sleep with them in the same bed, presence of animals in their houses, manner of dealing with animals outside their houses, and the type of building of their houses.

- Family history of itchy rash, and sharing clothes with others.

- Clinical data used for diagnosis: students were asked about the presence of rash in their bodies, its site, and time of appearance.

Finally, clinical examination was carried out in a private room in each school by a single trained female dermatologist for each student separately to detect the presence of scabies. The diagnosis of scabies was made on clinical basis by the presence of persistent pruritic rash with itching increasing at night, and skin lesions in the form of characteristic burrows, vesicles, and itchy papules or nodules in characteristic sites of the disease (on the wrist, sides and web spaces of the fingers, the axillae, periareolar, periumbilical, abdomen, and buttock areas), with liability to secondary infection with impetigo, folliculitis, or eczema.

\section{Statistical design}

Statistical analysis was done by using the software package for social studies (SPSS) version 19. The numerical variables were presented as the mean and standard deviation, while the categorical variables were presented as number and percentage. The crowding index was calculated by dividing the number of usual residents in a house by the number of bedrooms in the house. Factors predisposing to scabies were compared by odds ratio (OR) and 95\% confidence interval (CI). Binary logistic regression was performed to identify factors that can independently affect the occurrence of scabies. The level of significance was adopted at the 0.05 level.

\section{Results}

The sociodemographic characteristics of the included schoolchildren and the distribution of those children according to these risk factors are provided in Table 1. Females constituted $51.7 \%$ of the included children. Fifty-nine percent of the children studied were from rural schools, and $41 \%$ were from urban ones. Out of the children studied, 92 cases of scabies were detected (Figure 1 shows some of them) with a prevalence of $4.4 \%$.

Regarding paternal education, $40.5 \%$ of the schoolchildren's fathers were illiterate or had only primary education, while this number was higher for maternal education (44.4\%). Also, 52\% of the children's fathers were unemployed or manual workers, while $78.9 \%$ of the children's mothers were housewives (Table 1). 
Table I Sociodemographic characteristics of studied schoolchildren and distribution of children according to these risk factors for scabies

\begin{tabular}{|c|c|c|c|}
\hline Sociodemographic risk factors & Total number (\%) & Scabies cases n (\%) & OR $(95 \% \mathrm{Cl})$ \\
\hline \multicolumn{4}{|l|}{ Sex } \\
\hline Males & $\mathrm{I}, 017(48.3)$ & $40(3.9)$ & $0.815(0.535-1.242)$ \\
\hline Females & $\mathrm{I}, 087(5 \mathrm{I} .7)$ & $52(4.8)$ & \\
\hline \multicolumn{4}{|l|}{ Residence } \\
\hline Urban & $862(4 I)$ & $28(3.2)$ & $0.618^{*}(0.393-0.972)$ \\
\hline Rural & $1,242(59)$ & $64(5.2)$ & \\
\hline \multicolumn{4}{|l|}{ Father's education } \\
\hline Illiterate/primary & $851(40.5)$ & $5 I(6.0)$ & $1.885 *(1.237-2.870)$ \\
\hline Secondary/university & $1,253(59.5)$ & $4 \mid(3.3)$ & \\
\hline \multicolumn{4}{|l|}{ Mother's education } \\
\hline Illiterate/primary & $934(44.4)$ & $60(6.4)$ & $2.44 \mid *(1.575-3.873)$ \\
\hline Secondary/university & $\mathrm{I}, \mathrm{I} 70(55.6)$ & $32(2.7)$ & \\
\hline \multicolumn{4}{|l|}{ Father's job } \\
\hline Unemployed/manual worker & $\mathrm{I}, 093(52)$ & $65(5.9)$ & $2.304 *(1.459-3.640)$ \\
\hline Employee/professional/self-employed & $\mathrm{I}, 0 \mathrm{II}(48)$ & $27(2.7)$ & \\
\hline \multicolumn{4}{|l|}{ Mother's job } \\
\hline Housewife & $\mathrm{I}, 660(78.9)$ & $77(4.6)$ & \\
\hline Working & & $15(3.4)$ & $0.719(0.409-1.362)$ \\
\hline Manual worker & $84(3.99)$ & & \\
\hline Employee/professional/self-employed & $360(17.11)$ & & \\
\hline
\end{tabular}

Note: *Significant.

Among the schoolchildren studied, $3.9 \%$ of male children and $4.8 \%$ of female children were infested with scabies with no statistically significant difference (Table 1). Regarding residence, $3.2 \%$ of urban and $5.2 \%$ of rural schoolchildren were infested. Urban residence was found to lower the risk of scabies acquisition significantly $(\mathrm{OR}=0.618$, 95\% CI $=0.393-0.972$ ). Regarding education of parents, lower levels of parental education (illiterate or with only primary education) for either the father or the mother were found to increase the risk of scabies significantly $(\mathrm{OR}=1.885$, $\mathrm{CI}=1.237-2.870$ for paternal education; while $\mathrm{OR}=2.441$, 95\% CI $=1.575-3.873$ for maternal education) (Table 1 ).

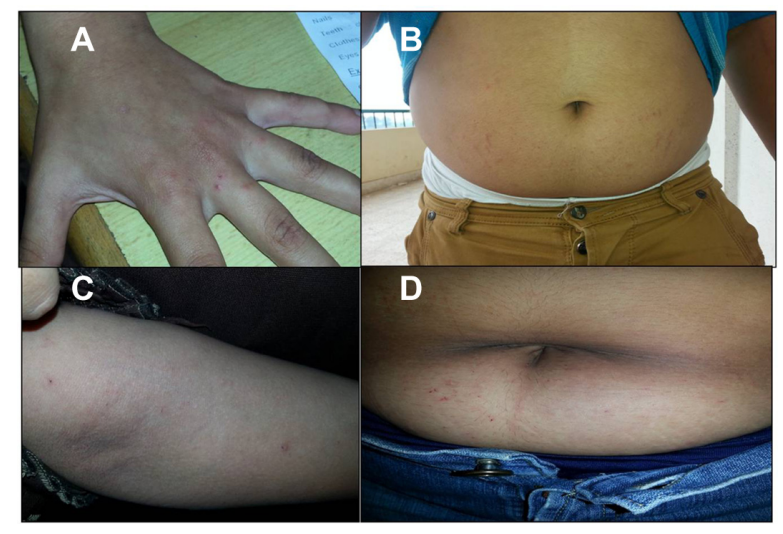

Figure I Scabies infestation in primary school children.

Notes: (A) Scabietic lesions in the web spaces of a female student at primary school. (B) Scabietic lesions around the umbilicus of a male student. (C) Scabietic lesions on the cubital fossa and forearm of a male student. (D) Scabietic lesions around the umbilicus of a female student.
The prevalence of infection among children with unemployed or manual worker fathers was significantly higher ( $\mathrm{OR}=2.304,95 \% \mathrm{CI}=1.459-3.640)$, while children with working mothers had a lower risk of acquiring scabies than those whose mothers were housewives, and the difference was insignificant $(\mathrm{OR}=0.719,95 \% \mathrm{CI}=0.409-1.362$ ) (Table 1).

Home environment characteristics of the schoolchildren studied and their relation to the risk of scabies infection are shown in Table 2. The crowding index was not found to affect the risk of infection with scabies significantly ( $\mathrm{OR}=0.892,95 \% \mathrm{CI}=0.456-1.743$ ), while those who used to sleep alone in bed had a significantly lower risk of scabies acquisition than those who shared a bed with others ( $\mathrm{OR}=0.468,95 \% \mathrm{CI}=0.277-0.790)$. Dealing with animals either inside or outside the house was found to increase the risk of scabies infection significantly ( $\mathrm{OR}=2.765,1.681$; $95 \% \mathrm{CI}=1.672-4.573,1.033-2.733$ respectively). Living in houses built by hard brick was associated with a lower risk of acquiring scabies (OR $=0.090,95 \% \mathrm{CI}=0.016-0.496$ ) (Table 2).

Table 3 shows the clinical history characteristics of the schoolchildren studied and the distribution of the children according to these risk factors for scabies; $20.7 \%$ of the included schoolchildren had a history of itchy skin rash within the preceding 2 weeks. About $15.8 \%$ of the children included had a history of a family member complaining of itchy skin lesions within the preceding 2 weeks, and $22.5 \%$ of those were actually infested by 
Table 2 Home environment characteristics of studied schoolchildren and distribution of children according to these risk factors for scabies

\begin{tabular}{|c|c|c|c|}
\hline Home environment risk factors & Total number (\%) & Scabies cases n (\%) & OR $(95 \% \mathrm{CI})$ \\
\hline \multicolumn{4}{|l|}{ Family size } \\
\hline 3 & $48(2.3)$ & & \\
\hline 4 & $343(16.3)$ & & \\
\hline 5 & $958(45.5)$ & & \\
\hline 6 & $473(22.5)$ & & \\
\hline 7 & I7| (8.I) & & \\
\hline 8 & $62(3.0)$ & & \\
\hline $9+$ & $49(2.3)$ & & \\
\hline \multicolumn{4}{|l|}{ Crowding index } \\
\hline$\leq \mathrm{I} .5$ & $1,792(85.2)$ & $10(4.0)$ & $0.892(0.456-1.743)$ \\
\hline$>1.5$ & $312(14.8)$ & $82(4.4)$ & \\
\hline \multicolumn{4}{|l|}{ Sleeping index } \\
\hline Alone & $706(33.55)$ & $18(2.5)$ & $0.468 *(0.277-0.790)$ \\
\hline With others & & $74(5.3)$ & \\
\hline With one person & $952(45.24)$ & & \\
\hline With two persons & $329(15.63)$ & & \\
\hline With three or more persons & $117(5.56)$ & & \\
\hline \multicolumn{4}{|l|}{ Having animals inside house } \\
\hline No & $894(42.5)$ & $20(2.2)$ & \\
\hline Yes & $1,210(57.5)$ & $72(6.0)$ & $2.765 *(1.672-4.573)$ \\
\hline \multicolumn{4}{|l|}{ Dealing with animals outside house } \\
\hline No & I,748 (83.I) & $69(3.9)$ & \\
\hline Yes & $356(16.9)$ & $23(6.5)$ & $1.68 \mathrm{I} *(1.033-2.733)$ \\
\hline \multicolumn{4}{|l|}{ Type of building } \\
\hline Hard brick & $2,098(99.7)$ & $90(4.3)$ & $0.090 *(0.016-0.496)$ \\
\hline Soft brick & $6(0.3)$ & $2(33.3)$ & \\
\hline
\end{tabular}

Note: *Significant.

scabies where that risk factor had a statistical significance (OR $=29.99$, 95\% CI =17.44-51.60). Sharing clothes with other family members was reported by $34.3 \%$ of children, and this habit was found to significantly increase the risk of scabies infection $(\mathrm{OR}=2.492,95 \%$ $\mathrm{CI}=1.635-3.797$ ).

Table 4 summarizes the results of the binary logistic regression analysis of the factors related to the risk of sca- bies infection after controlling for potential confounders. Independently related factors included a lower level of maternal education, and a family history of itchy rash within the preceding 2 weeks (positive predictors of scabies), in addition to sleeping alone, not having animals in the house, and home building made of hard brick, which were all found to be negative predictors of scabies (all $P<0.05)$.

Table 3 Clinical history characteristics of studied schoolchildren and distribution of children according to these risk factors for scabies

\begin{tabular}{|c|c|c|c|}
\hline Clinical history risk factors & Total number (\%) & Scabies cases n (\%) & OR $(95 \% \mathrm{Cl})$ \\
\hline \multicolumn{4}{|c|}{ History of itchy skin rash within last 2 weeks } \\
\hline No & $\mathrm{I}, 668(79.3)$ & $51(3.05)$ & \\
\hline Yes & $436(20.7)$ & $4 \mathrm{I}(9.4)$ & $2.21 *(1.098-3.91 I)$ \\
\hline \multicolumn{4}{|c|}{ Family member with itchy skin lesion within last 2 weeks } \\
\hline No & I,77I (84.2) & $17(1.0)$ & \\
\hline Yes & $333(15.8)$ & $75(22.5)$ & $29.99 *(17.44-51.60)$ \\
\hline \multicolumn{4}{|c|}{ Sharing clothes by family members } \\
\hline No & $1,383(65.7)$ & $4 \mid(3.0)$ & \\
\hline Yes & $721(34.3)$ & $51(7.1)$ & $2.492 *(1.635-3.797)$ \\
\hline
\end{tabular}

Note: *Significant. 
Table 4 Multivariate analysis of risk factors affecting scabies infection among studied schoolchildren

\begin{tabular}{|c|c|c|c|}
\hline Variable & $\begin{array}{l}\text { Wald's } \\
\text { test value }\end{array}$ & $\boldsymbol{P}$ & $95 \% \mathrm{Cl}$ of $\exp \mathrm{B}$ \\
\hline \multicolumn{4}{|l|}{ Mothers' education } \\
\hline Illiterate/Primary & 5.365 & $0.021 *$ & I.II8-3.796 \\
\hline Secondary/University & Referent & & \\
\hline \multicolumn{4}{|l|}{ Sleeping } \\
\hline Alone & 5.106 & $0.024 *$ & $0.319-0.922$ \\
\hline With others & Referent & & \\
\hline \multicolumn{4}{|c|}{ Having animals in the house } \\
\hline No & 10.377 & $0.001 *$ & $0.255-0.717$ \\
\hline Yes & Referent & & \\
\hline \multicolumn{4}{|l|}{ Type of building } \\
\hline Hard brick & 6.815 & $0.001 *$ & $0.017-0.558$ \\
\hline Soft brick & Referent & & \\
\hline \multicolumn{4}{|c|}{ Family history of itchy skin lesion } \\
\hline No & Referent & & \\
\hline Yes & 6.776 & $0.009 *$ & $1.181-3.257$ \\
\hline
\end{tabular}

\section{Discussion}

Epidemiological data about scabies infestation in schoolchildren provide valuable information about its risk factors and suggest a basis for methods of prevention and therapy. ${ }^{6}$

In this study, the overall prevalence of scabies in schoolchildren was $4.4 \%$ in the area studied. In a study done among schoolchildren in Ibadan, Nigeria, and in another study done on pediatric dermatology clinic patients in Kuwait, the prevalence of scabies was $4.8 \%$ and $3 \%$, respectively. ${ }^{7.8}$

On the other hand, high prevalence rates of scabies were reported among Indian children ${ }^{9}$ and among children in $\operatorname{Karachi}^{10}(10.16 \%$, and $23.9 \%$, respectively), and this could be attributed to density of population, overcrowding, and poverty in these localities.

In the current study, the difference in the prevalence of scabies between males and females was not statistically significant. This result was in agreement with the results of other studies in countries like Nigeria ${ }^{11}$ and Turkey. ${ }^{12}$ On the other hand, male predominance was observed in other Indian studies, ${ }^{13,14}$ and this might be related to private social factors in each society or country.

The present study showed that the prevalence of scabies was higher among children from rural schools than among those from urban ones. Many other studies from other countries also support this finding. ${ }^{13-15}$ This finding could be explained by larger family size in rural areas, leading to overcrowding, in addition to the decreased level of health education, poverty, bad behavioral habits such as sharing clothes and bed linen with others, and dealing with animals.
In agreement with a number of previous studies, ${ }^{12,16}$ lower maternal education levels and nonworking mothers were found to predispose to scabies acquisition, with infestation found to be more frequent among children whose mothers were illiterate or only primarily educated housewives. It could be stated that educated mothers are more able to appreciate and utilize disease prevention and health care services for their children.

The prevalence of scabies in the present study was higher among children whose fathers were illiterate or only primarily educated, and also among those whose fathers were unemployed or manual workers. These results are in line with those of previous studies, which also demonstrated that illiteracy of adult household members was a very good predictor of the presence of scabies in developing and industrialized countries. ${ }^{16-18}$ The education and occupation of the fathers are determinants of social class, and as the paternal level of education improves, the family income and hence availability of seeking better medical consultation also improves.

In the present study, it was found that sleeping with others, having animals in the house, dealing with animals outside the house, living in houses made of soft brick, having a family history of itchy skin lesions, and sharing clothes with others were all significant risk factors for scabies infestation. Many studies in our country and other countries also support these findings. ${ }^{19-22}$ Feldmeier et $\mathrm{al}^{17}$ reported that illiteracy, low income, poor housing (absence of a solid floor, no access to electricity, no toilet in the compound), and sharing clothes and towels with other family members were all significant risk factors for the presence of scabies.

Karim et $\mathrm{al}^{16}$ demonstrated that children who slept on the floor with other children contracted more severe infection and became reinfected in greater proportions. This facilitates skin-to-skin contact and therefore the spread of scabies mites from infested to healthy children, as reported in Brazil, ${ }^{20}$ Argentina, ${ }^{21}$ and Egypt. ${ }^{22}$ These findings could implicate close contact and the sharing of beds in the transmission of the scabies mite. On the other hand, Hay et $\mathrm{a}^{23}$ reported that blankets and clothing do not appear to be important in the transmission of scabies, and that there is no conclusive evidence to suggest that washing of clothing and blankets is necessary for the prevention of scabies spread. Hay et $\mathrm{al}^{23}$ demonstrated that the mite is an obligate parasite and is highly susceptible to dehydration when off the host. At temperatures below $20^{\circ} \mathrm{C}$, mites are almost immobile.

In our study, the crowding index did not have a significant impact on the prevalence of scabies. In contrast, Landwehr et $\mathrm{al}^{24}$ and Wendel and Rompalo ${ }^{25}$ reported that 
overcrowding is one of the predisposing risk factors for the transmission of scabies. Johnston and Sladden ${ }^{26}$ also demonstrated that overcrowding is believed to have a significant effect on the spread of scabies, reflecting the fundamental role of physical contact in person-to-person transmission. They also demonstrated that a history of itching in several family members over the same period is almost pathognomonic. ${ }^{25}$ However, lack of history of itching in family members does not exclude scabies.

Collectively speaking, the relationship between the prevalence of scabies and the relative levels of poverty, crowding, and hygiene within a community is complex. In addition, school environments increase the vulnerability of crossinfection, which can be passed to family members.

\section{Limitations}

The following limitations of the study have to be taken into consideration. First, data collection through cross-sectional study design may imply biased information, especially regarding hygiene habits (such as sharing clothes with others, and dealing with animals outside the house), with potential overreporting of favorable behaviors, for which controlling was difficult. Second, the study included children of young age who might have needed paternal cooperation in filling the questionnaire, but this was not possible. Third, diagnosis was carried out only on a clinical basis; however, owing to the large number of students and the time factor, it was not possible to validate confirmative burrow scraping and microscopic examination for all diagnosed cases. Finally, the study was conducted only during the autumn and winter seasons owing to the limits of the school time and summer holidays, and this might have influenced the prevalence of scabies as scabies is claimed to show higher incidence during the winter months; however, detecting and controlling this confounder was also difficult.

\section{Conclusion}

In conclusion, the findings of the current study confirm that scabies is still an important health problem affecting schoolchildren in our community, especially in rural areas. Poor living conditions (inadequate housing, sleeping with others, illiteracy, having animals in the house, dealing with animals outside the house, and sharing clothes with others) are important risk factors for transmission of scabies. Performing similar community-based studies on a larger scale and in different governorates in Egypt is recommended to throw light on the actual magnitude of scabies and other infectious diseases and health problems, particularly among schoolchildren of different ages. In addition, regular visits by medical staff and periodic clinical check-ups for schoolchildren, particularly in rural areas, to provide treatment and health education would be very beneficial.

\section{Disclosure}

The authors report no conflicts of interest in this work.

\section{References}

1. Karthikean K. Treatment of scabies: newer perspectives. Postgrad Med J. 2005;81:7-11.

2. Walton SF, Holt DC, Currie BJ, Kemp DJ. Scabies: new future for a neglected disease. Adv Parasitol. 2004;57:309-376.

3. Feldmeier H, Heukelbach J. Epidermal parasitic skin diseases: a neglected category of poverty-associated plagues. Bull World Health Organ. 2009;87:152-159.

4. Chosidow O. Clinical practices. Scabies. N Engl J Med. 2006;354(16): 1718-1727.

5. Ezz El-Dawela R, Fatehy AA, Elmoneim AA. Prevalence of skin diseases among school children: a survey in the Sohag Governorate. J Egypt Women Dermatol Soc. 2012;9:47-51.

6. Saurabh S, Sahu SK, Sadishkumar A, et al. Screening for skin diseases among primary school children in a rural area of Puducherry. Indian $J$ Dermatol Venereol Leprol. 2013;79:268.

7. Ogunbiyi AO, Owoaje E, Ndahi A. Prevalence of skin disorders in school children in Ibadan, Nigeria. Pediatr Dermatol. 2005; 22:6-10.

8. Nanda A, Al-Hasawi F, Alsaleh QA. A prospective survey of pediatric dermatology clinic patients in Kuwait: an analysis of 10,000 cases. Pediatr Dermatol. 1999;16:6-11.

9. Sardana K, Mahajan S, Sarkar R, et al. The spectrum of skin disease among Indian children. Pediatr Dermatol. 2009;26:6-13.

10. Javed M, Jairamani C. Pediatric dermatology: an audit at Hamdard University Hospital, Karachi. J Pac Assoc Dermatol. 2006;16: 93-96.

11. Sambo MN, Idris SH, Umar AA, et al. Prevalence of scabies among school-aged children in Katanga rural community in Kaduna state, Northwestern Nigeria. Ann Nigerian Med. 2012;6:26-29.

12. Ciftci IH, Cetinkaya Z, Dogru O, Cetinkaya Z, Kulac M. Prevalence of pediculosis and scabies in preschool nursery children of Afyon, Turkey. Korean J Parasitol. 2006;44:95-98.

13. Sehgai VN, Rao TL, Rege VL, Vadiraj SN. Scabies: a study of incidence and a treatment method. Int J Dermatol. 1972;11:106.

14. Yaseen U, Hassan I. Prevalence of various skin disorders in school going children of Kashmir valley of North India: a cross-sectional study. Indian J Paediatr Dermatol. 2013;14:67-72.

15. Amin TT, Ali A, Kaliyadan F. Skin disorders among male primary school children in Al Hassa, Saudi Arabia: prevalence and socio-demographic correlates-a comparison of urban and rural populations. Rural Remote Health. 2011;11:1517.

16. Karim SA, Anwar KS, Khan MA, et al. Socio demographic characteristics of children infested with scabies in densely populated communities of residential madrashas (Islamic education institutes) in Dhaka, Bangladesh. Public Health. 2007;121:923-934.

17. Feldmeier H, Jackson A, Ariza L, et al. The epidemiology of scabies in an impoverished community in rural Brazil: presence and severity of disease are associated with poor living conditions and illiteracy. J Am Acad Dermatol. 2009;60:436-443.

18. Stanton B, Khanam S, Nazrul S, Nurani S, Khair T. Scabies in urban Bangladesh. Am J Trop Med Hyg. 1987;90:219-226.

19. Hegazy AA, Darwish NM, Abdel-Hamid IA, Hammad SM. Epidemiology and control of scabies in an Egyptian village. Int $J$ Dermatol. 1999;38:291-295. 
20. Heukelbach J, Oliveira FA, Fedmeier H. [Ectoparasitoses and public health in Brazil: challenges for control]. Cad Sauda Publica. 2003;19:1535-1540. Portuguese.

21. Chouela E, Abeldano A, Pellerano G, Hernández MI. Diagnosis and treatment of scabies: a practical guide. Am J Clin Dermatol. 2002;3:9-18.

22. Morsy TA, El-Ela RG, Morsy AT, Nassar MM, Khalaf SA. Two contagious ectoparasites in orphanage children in Nasr City, Cairo. J Egypt Soc Parasitol. 2000;30:727-734.

23. Hay RJ, Steer AC, Engelman D, Walton S. Scabies in the developing world - its prevalence, complications, and management. Clin Microbiol Infect. 2012;18:313-323.
24. Landwehr D, Keita SM, Pönnighaus JM, Tounkara C. Epidemiologic aspects of scabies in Mali, Malawi, and Cambodia. Int J Dermatol. 1998;37:588-590.

25. Wendel K, Rompalo A. Scabies and pediculosis pubis: an update of treatment regimens and general review. Clin Infect Dis. 2002;35: $146-151$.

26. Johnston G, Sladden M. Scabies: diagnosis and treatment. BMJ. 2005;17:619-622.

\section{Publish your work in this journal}

Clinical, Cosmetic and Investigational Dermatology is an international, peer-reviewed, open access, online journal that focuses on the latest clinical and experimental research in all aspects of skin disease and cosmetic interventions. All areas of dermatology will be covered; contributions will be welcomed from all clinicians and basic science researchers globally. This journal is indexed on CAS. The manuscript management system is completely online and includes a very quick and fair peer-review system, which is all easy to use. Visit http://www.dovepress.com/testimonials.php to read real quotes from published authors.

Submit your manuscript here: http://www.dovepress.com/clinical-cosmetic-and-investigational-dermatology-journal 